\title{
CLIMATERIO Y MENOPAUSIA
}

\author{
Dr. Luis Fernando Luzardo M.* \\ Dr. Eduardo Pérez Gómez* \\ Dr. Carlos Castro Lobo* \\ Dr. Ramiro Zúñiga G.** \\ Dr. Gonzalo Uribe Botero***
}

Ponencia presentada por la Sociedad Nortesantandereana de Ginecología y Obstetricia al Octavo Congreso Colombiano de la Especialidad.

\section{Introducción}

Climaterio viene del griego "Klimacter", que significa "un peldaño de la escalera". La gran evolución de la ciencia médica ha determinado un aumento en la longevidad. En la era cristiana el promedio de vida alcanzaba los 25 años; en el siglo XIV dicho promedio se encontraba situado por encima de los 30 años; en la alborada de nuestro siglo, hacia los 50 años, y en la era de las conquistas especiales el ser humano que nazca puede esperar a sobrevivir los 70 años. En otra forma, hace 60 años la mayoría de las mujeres no lograban vivir hasta exceder los años de la vida sexual activa; en la actualidad, casi todas las mujeres alcanzan a sobrepasar en 2 o 3 decenas de años la menopausia.

Aunque el ser humano es de los vivientes el más desvalido al nacer, entre las especies animales la mujer es la única hembra que vive mucho más allá de sus años fértiles; de esta conquista médica ante el mar vital han surgido nuevos enfoques en el manejo de las etapas avanzadas de la vida, y el climaterio y la senectud son temas de actualidad.

La gónada femenina que inicia desde muy temprana época embrionaria su función, en las formaciones retrocelómicas, determina con esta iniciación y con la cesación de su función dos etapas primordiales en la vida de la mujer: la pubertad y el climaterio.

El climaterio, período de transición de la madurez a la vejez, cubre aproximadamente 15 años de vida. Es una fase regresiva; es más pręcoz en la mujer que en el hombre, porque por razones todavía desconocidas, la vida funcional del ovario es mucho más corta y su involución más rápida, que la de los testículos. Dicho proceso crea un desequilibrio prolongado, aunque temporal, del sistema endocrino, que determina mani-

* Médico Adjunto al Departamento GinecoObstétrico del Hospital San Juan de Dios. Cúcuta.

** Médico Jefe del Servicio de Ginecología del Hospital San Juan de Dios. Cúcuta.

*** Médico Jefe del Departamento de Patología del Hospital San Juan de Dios. Cúcuta. 
festaciones serias en un $10 \%$ de las mujeres y moderadas en un $20 \%$ adicional. La rapidez del proceso involutivo parece ser responsable de la severidad de las manifestaciones, porque como lo observó Shelton, existen fisiológicamente hablando dos tipos de mujeres en el climaterio: unas, sufren una supresión más bien rápida y completa de los estrógenos, seguida por cambios acelerados de piel, huesos, mamas, etc., y otras, que aunque pueden dejar de menstruar, continúan elaborando esteroides sexuales durante 10 a 15 años.

De acuerdo con las anteriores consideraciones podemos definir el climaterio como la época de la vida de la mujer caracterizada por el descenso de la actividad endocrina del ovario y la supresión de su actividad gametogénica, que comienza antes de la menopausia y persiste después que ha cesado el flujo catamenial. La cesación de la expresión externa del ciclo genital se considera como Menopausia. El estado general de la salud, las enfermedades ginecológicas, la multiparidad, la herencia, la raza, etc., influyen en el climaterio. Si consideramos la menopausia como un signo y el climaterio como una época, y si pensamos que anteriormente a la cesación de la menstruación ya han tenido lugar cambios en el estado general y a nivel local genital, y que posteriormente a la supresión de la menstruación continúa el proceso deprivativo, hemos considerado muy útil la clasificación de climaterio propuesta por Mateos cándano y cols. (4):

19( Climaterio Premenopáusico, caracterizado por un descenso de la actividad lútea y una etapa de "esterilidad fisiológica". Sabemos que previamente a la infecundidad fisiológica premenopáusica existe una etapa de infertilidad preclimatérica carac- terizada por un aumento en el porcentaje de partos prematuros, abortos y malformaciones congénitas. Los ovarios, debido a los ciclos anovulatorios presentan estados comparables a la poliquistosis (47); el endometrio, sin evidencia secretora, nos muestra cuadros desde el simple proliferativo, hasta los hiperplásicos, en sus diversas variedades. La citología funcional evidencia en los índices cariopicnótico y de maduración, un descenso de la actividad estrogénica. Clínicamente encontramos los trastornos menstruales que van desde la espaniomenorrea hasta las polihipermenorreas y metrorragias. Como veremos más adelante, hacen su aparición los síntomas psicoemocionales y los fenómenos neurovegetativos.

2: Climaterio Menopáusico: su signo cardinal es la cesación de la menstruación. Dicho signo se debe a la desaparición de las oscilaciones cíclicas hormonales que ocasionan deprivaciones, y a tasas estrogénicas inferiores a las requeridas para determinar una suficiente proliferación endometrial.

3․ Climaterio Postmenopáusico: caracterizado por la inactividad ovárica; el endometrio en su mayoría es de tipo atrófico; se reduce el tamaño del útero; hay pérdida del trofismo vaginal y se presentan las demás manifestaciones de la involución del aparato genital. La citología vaginal y las dosificaciones sanguíneas y urinarias, nos demuestran una actividad estrogénica ovárica nula o mínima.

\section{Material y Métodos}

Para el desarrollo de este trabajo hemos estudiado 80 pacientes de la consulta externa de Ginecología del Hospital San Juan de Dios de Cúcuta, cuya única condición era encon- 
trarse entre los 40 y los 55 años, edades que son consideradas clásicamente como límites del período climatérico. Se incluyeron 3 casos de edades inferiores que presentando amenorrea secundaria de larga duración, llenaron los criterios diagnósticos para ser considerados como menopausia precoz. Este estudio fue realizado desde Abril 6 de 1968 hasta Julio 31 de 1969; estimamos de suma importancia para la valoración global de los resultados, el anotar que casi el $100 \%$ de este material humano correspondió a un nivel socioeconómico y cultural extraordinariamente bajo, contándose entre ellas no pocas analfabetas; estos factores contribuyeron a acrecentar las dificultades para obtener su colaboración en el cumplimiento de controles, citas a laboratorio, manera de recoger muestras, administración de drogas, etc. La carencia de recursos técnicos condicionada por ser nuestro Hospital de provincia, nos limitó en la ejecución de ciertas dosificaciones hormonales de importancia capital en un estudio de esta naturaleza, tales como las referentes a pregnandiol, FSH y $L H$, vacíos que tratamos de subsanar en la medida de nuestras capacidades, dando como ejemplo el caso de la prueba de respuesta ovárica a la administración de gonadotropina sérica (27). Nuestras pacientes fueron sometidas a la siguiente metodología :

19. Historia clínica completa, haciendo hincapié en los antecedentes gineco-obstétricos, sintomatología ginecológica actual, síntomas generales relacionados o no con el estudio y síntomas psicoemocionales.

$2{ }^{\circ}$ Examen físico general con especial referencia al examen ginecológico incluyendo las glándulas mamarias.

\section{3․ Fotofluorografía pulmonar.}

4․ Exámenes de laboratorio generales: biometría hemática, glicemia, colesterolemia, proteinemia, relación serinas globulinas, serología, azoemia, uranálisis y coproanálisis.

5? Frotis del exudado vaginal para estudios bacteriológicos.

6: Dosificación de 17 Cetoesteroides en orina de 24 horas.

7: Yodo plasmático ligado a la proteína.

8. Citología vaginal exfoliativa de Papanicolaou para evaluación citohormonal y detección de cáncer.

9: Biopsia de endometrio mediante cureta de Novak para estudios funcionales, histoquímicos y anatomopatológicos.

10. Valoración del FSH por medio de la citología en casos con citologías hipoestrogénicas 0 francamente atróficas.

11. Biopsias cervicales en casos de citologías sospechosas.

12. Radiografías de huesos largos y columna lumbosacra en casos sospechosos de osteoporosis.

\section{Análisis de los resultados}

La edad de las pacientes osciló entre los 33 y 55 años, de las cuales 3 se encontraban en menopausia precoz. $48(60 \%)$ en climaterio premenopáusico y $32(40 \%)$ en climaterio menopáusico. De los 3 casos clasificados como menopausia precoz, el primero correspondió a una mujer de 35 años de edad en amenorrea de un año después de castración quirúrgica; el segundo se trataba de una paciente de 37 años de edad con $11 \frac{1}{2}$ años de amenorrea, antecedentes de 


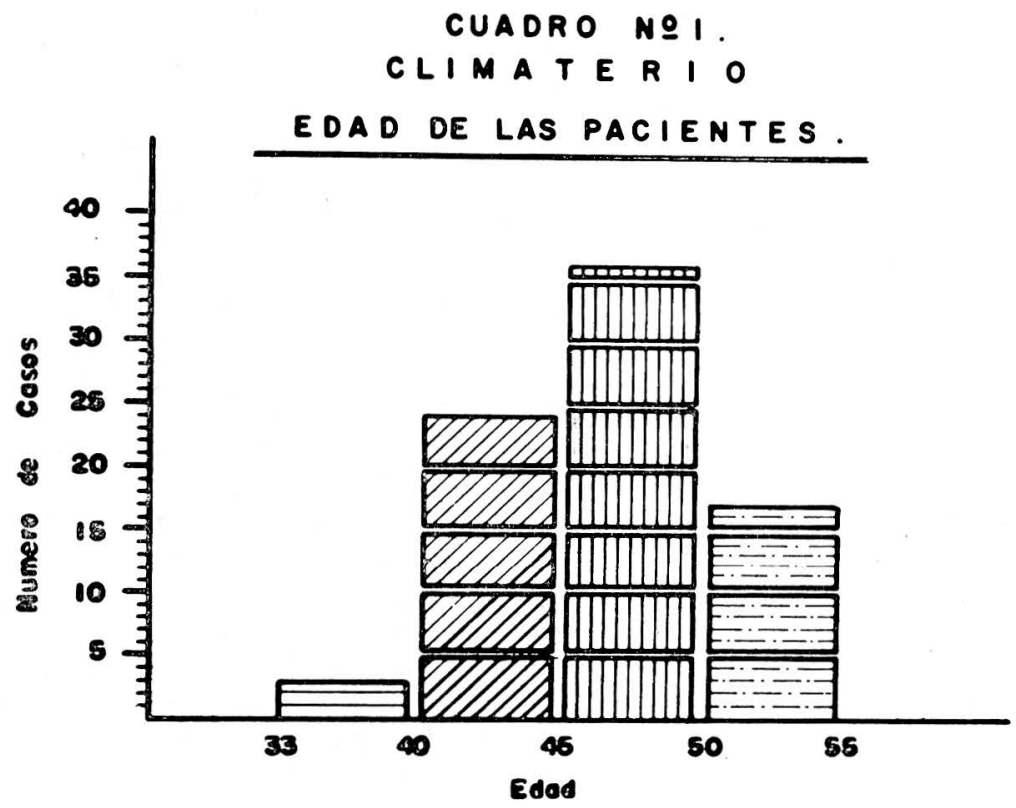

pelviperitonitis postaborto que fue tratada mediante colpotomía y posteriormente lavado peritoneal 6 años atrás, y el tercero, paciente de 33 años en amenorrea de 9 años luego de un parto, con manifestaciones clínicas y de laboratorio de hipopituitarismo.

\section{CUADRO MO 2 \\ CLIMATERIO}

ESTADO MEMSTRUAL

Se entiende como menapausia precoz la cesación de las menstruaciones antes de los 40 años de edad; su frecuencia oscila alrededor del $8 \%$ de las pacientes (24 - $41-48$ ). Los factores etiológicos son variados y comprenden: trastornos de la fórmula cromosómica, hereditarios de tipo familiar, hipopituitarismo severo, factores ováricos e iatrogénicos. La tríada diagnóstica básica comprende la amenorrea, la elevación de las tasas de gonadotropinas y la desviación del índice de maduración citológico hacia la izquierda. Actualmente se tiene la certeza de que la pérdida de secreción estrogénica del

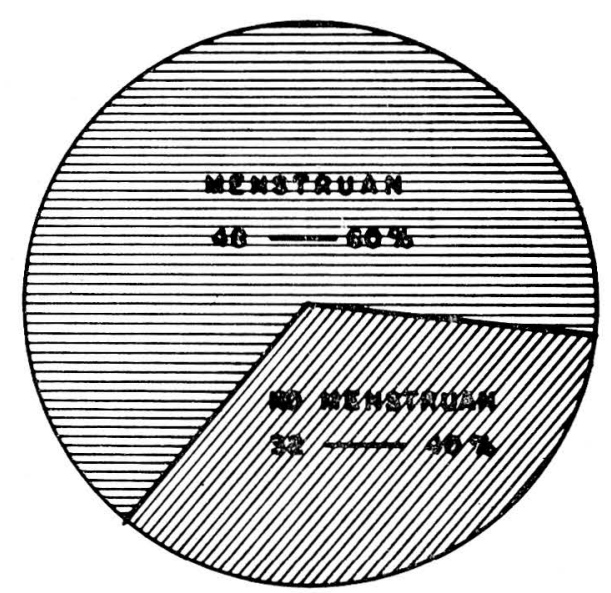


ovario puede llevar a la aterosclerosis y a la osteoporosis precoz (12 36 - 37); existen numerosas pruebas tanto de observaciones clínicas como de anatomía patológica, de que las mujeres con menopausia precoz ya sea de origen espontáneo o quirúrgicamente inducida, presentan una susceptibilidad aumentada a la aterosclerosis de las coronarias.

\section{Edad al cesar las menstruaciones}

La distribución por edades de cesación de la menstruación en el grupo de 32 casos de climaterio menopáusico, nos muestra una distribución uniforme entre los 40 y los 52 años con un discreto aumento hacia los 47, el cual corresponde a la edad promedio dada por varios autores (35 - 33), anotando que el 12,5\% de nuestra casuística estaba menstruando o había cesado su menstruación después de los 50 años, lo que también está de acuerdo con lo referido por Novak Seegar y otros.

\section{Paridad}

Solamente 4 pacientes (5\%) eran nulíparas; el $11,25 \%$ habían tenido un solo embarazo, y las restantes tuvieron múltiples gestaciones que como lo vemos en el Cuadro, oscilaron entre 2 y 18, haciendo hincapié en que el $27,50 \%$ tuvieron entre 8 y 9 gestaciones. El número global de embarazos fue de 615 correspondiendo esta cifra a un promedio de 8 por paciente; de ellos terminaron en aborto de causa indeterminada 58, es decir el $9,43 \%$, lo que en términos generales está de acuerdo con el porcentaje de gestaciones fallidas. Las cifras anteriormente expuestas se nos ocurren realmente alarmantes, traduciendo el alto índice de fecundidad de nuestras mujeres, constituyéndose en un argumento a fa-

CUADRO N. 3

CLI MATER IO

EDAD AL CESAR LA MENSTRUACION

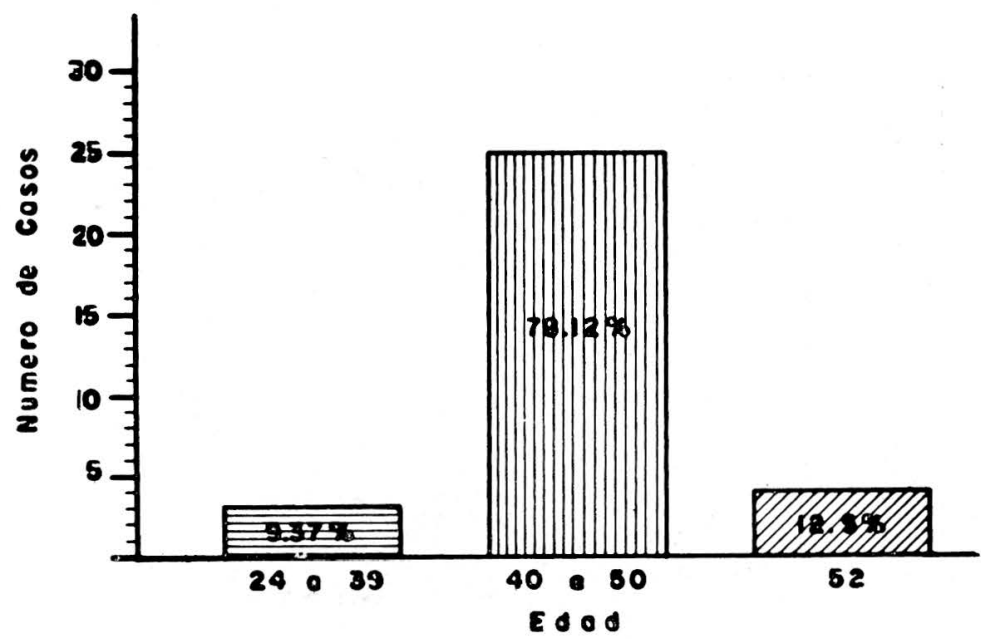




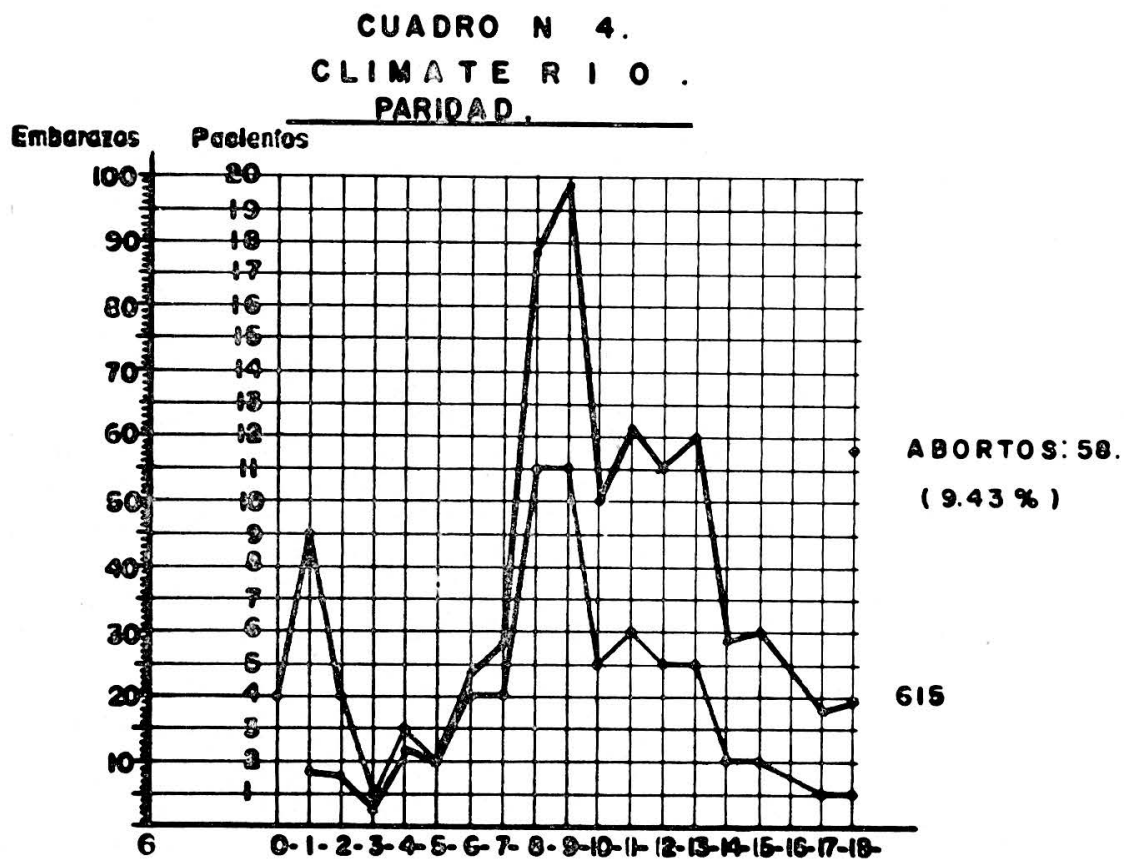

GUADRO N 5

CLIMATERIO

FECHA ULTIMO PARTO

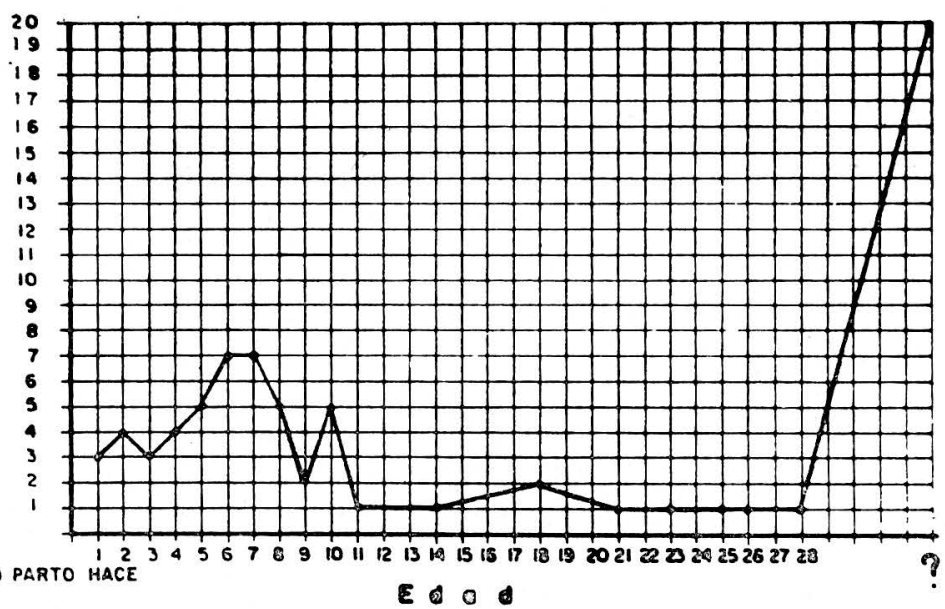


vor de las campañas relacionadas con la planificación familiar, si tenemos en cuenta el bajo nivel socioeconómico y cultural de la mayoría de las mujeres que asisten a nuestras consultas hospitalarias.

\section{Enfermedades generales asociadas CUADRO № 6 \\ CLIMATERIO \\ ENFERMEDADES GENERALES ASOCIADAS}

\begin{tabular}{lc}
\hline Enfermedad & $N^{0}$ de Casos \\
\hline Obesidad & 12 \\
Lúes & 10 \\
Osteoporosis & 7 \\
Hipertensión arterial & 4 \\
Hernia umbilical & 4 \\
Diabetes & 4 \\
Pielonefritis & 3 \\
Hipertiroidismo & 3 \\
Colitis nocio nodular & 3 \\
Várices de miembros inferiores & 2 \\
Espóndilo artrosis lumbar & 2 \\
Artritis reumatoidea & 2 \\
Hernia ventral postoperatoria & 1 \\
Colecistitis & 1 \\
Urolitiasis & 1 \\
Vicio de refracción & 1 \\
Discracia sanguínea & 1 \\
Carcinoma metastásico & 1 \\
Lepra pulmonar & 1 \\
T.B.C. pún de Sheehan & 1 \\
Síndrome deris renal & 1 \\
Ptosis & 1 \\
\hline
\end{tabular}

En el Cuadro podemos observar que las enfermedades sobreagregadas que inciden con mayor frecuencia sobre la salud de estas pacientes, son las que debido a la etapa de vida en que se encuentran son aceptadas universalmente tales como la obesidad, la hipertensisón arterial, la diabetes. Queremos resaltar el alto número de casos encontrados de Lúes, lo mismo que los de osteoporosis, entidad ésta que no esperábamos hallar en tan alto porcentaje, si tenemos en cuenta que la mayor de nuestras mujeres se encontraba en los 55 años.

El peso corporal aumenta en forma gradual de los 20 a los 65 años manteniéndose en adelante constante hasta los 80 cuando empieza a decrecer. Debido al transcurso de los años todos los mecanismos homeostáticos sufren alteraciones en su capacidad funcional, hecho comprobado en la persona de edad avanzada, la cual tiene disminuída su capacidad para regular la frecuencia del pulso, la tensión arterial, la glicemia y el $\mathrm{Ph}$ sanguíneo. La utilización del oxígeno y el balance nitrogenado disminuyen, representando una manifestación de la menor reserva de estos mecanismos homeostáticos.

Sin existir pruebas muy notables, se dice que existe relación entre el climaterio e hiperactividad generalizada de la adenohipófisis traducida en una mayor secreción de gonadotropinas y otras hormonas como el ACTH y la TSH. Dicho fenómeno guardaría relación con un aumento de la actividad tiroidea en la iniciación del climaterio, aunque la mayoría de las mujeres, como lo demuestran los valores del metabolismo, el Y ligado a las proteínas y la fijación del $Y$ 131, se encuentran dentro de los límites de la normalidad (6).

La osteoporosis se define como una disminución de la masa y de la densidad óseas, lo que quiere decir, que el hueso contiene menor cantidad de tejido y más espacios medulares $(36$ - 37). De este modo el hueso al ser más poroso se torna más frágil, acentuándose la tendencia a las fracturas espontáneas. Se ha podido comprobar que esta disminución de la masa ósea en el decurso de los años es mayor y más precoz en las mujeres que en los hombres. Existen diversas teorías pa- 
ra explicar estos hechos: Casuccio (9) cree que depende de restricción de la actividad osteoblástica con una disminución de la vascularidad, y no del hipoestrogenismo. Harrison (10) lo asimila a una deficiencia de la utilización del calcio y a un desequillibrio entre la actividad osteoblástica y la osteoclástica. Reifenstein (11) a la falta de acción anabólica de los esteroides córticosuprarrenales y de los estrógenos (7 - 8).

Existe íntima relación entre los esteroides circulantes y el metabolismo celular; se presentan modificaciones en la regulación del balance hidroelectrolítico y de la permeabilidad celular al instalarse la disminución o la pérdida de la actividad estrogénica. La calcemia y la actividad osteoblástica en relación con la función estrogénica parecen estar tan íntimamente relacionados, que la osteoporosis es un fenómeno casi constante en la postmenopausia; ella representa el $25 \%$ de los problemas ortopédicos en las mujeres de edad avanzada. Aunque no corresponde exactamente a la edad de menopausia que estudiamos no podemos dejar de lado la consideración del problema de la aterosclerosis. Desde el reconocimiento de Herrick (13) de la oclusión coronaria aguda no mortal como síndrome clínico, muchas observaciones se han hecho sobre la aterosclerosis. Una y muy importante, es la de que existen un gran número de pruebas acerca de que antes de la menopausia es casi tres veces más frecuente en los varones que en las hembras de la misma edad, mientras que al declinar la función endocrina del ovario manifestada por la disminución paulatina de los niveles estrogénicos, la proporción se hace sensiblemente igual en los dos sexos. Parece un hecho demostrado que la secreción de estrógenos prote- ge de manera importante a la mujer premenopáusica de la cardiopatía coronaria prematura; el mecanismo de esta acción se relaciona con los efectos de los estrógenos sobre los lípidos plasmáticos. Los fosfolípidos, el colesterol y los triglicéridos se encuentran asociados con proteínas específicas tales como las lipoproteínas plasmáticas. Estas lipoproteínas en el plasma en ayunas son de 3 clases: alfa lipoproteínas (de elevada densidad), que contienen más fosfolípidos que colesterol y carecen de triglicéridos; beta lipoproteínas (de baja densidad) que contienen la mayor parte del colesterol circulante; pre beta lipoproteínas (de muy baja densidad) ricas en triglicéridos. En las mujeres no menopáusicas los niveles plasmáticos de alfa lipoproteínas son más elevados y los de beta lipo proteínas más bajos que en los hombres; esto se refleja por concentraciones menores de colesterol plasmático y su relación colesterol - fosfolípidos. El papel de los estrógenos en el mantenimiento de estos niveles se muestra muy importante; se ha comprobado que en la menopausia, sea natural o inducida, el tipo de lipoproteína plasmática es similar al del varón. La administración de estrógenos conduce a una disminución de las beta lipoproteínas y a un aumento de las alfa lipoproteínas.

De estas demostraciones y de observaciones clínicas de varios autores, sobre la mayor incidencia de aterosclerosis en mujeres ooforectomizadas, se deriva la tendencia actual en aconsejar no efectuar la ovariectomía bilateral como método profiláctico al practicar la histerectomía en la perimenopáusica (44). El hecho de que diversas investigaciones a largo plazo y con resultados muy alentadores hayan comprobado la acción antiaterógena de los estrógenos, 
para su utilización por tiempo prolongado en las postmenopáusicas con signos de cardiopatía coronaria y en las mismas que presenten otros factores predisponentes tales como el tabaquismo, diabetes, obesidad, hipercolesterolemia, hipertensión arterial, etc. $(12-51)$.

\section{Patología Ginecológica concomitante}

Sin intentar ofrecer datos de valor estadístico significativo ya que nuestro limitado número de casos lo impide, nos permitimos observar que las entidades ginecológicas que priman en estas pacientes son los trastornos de la estática genital, seguidos por un alto índice de procesos inflamatorios dentro de los cuales se des- tacan con un $48,7 \%$ las vaginitis de diversa etiología.

El alto número de embarazos y de partos en su gran mayoría sin atención médica adecuada, las malas condiciones de salud y nutrición, la intensa actividad física de tipo laboral obligada por el bajo nivel socioeconómico y la pérdida de resistencia y elasticidad tisulares determinadas por la edad y la declinación de la función estrogénica, nos explican el porcentaje tan elevado de procesos de la índole del prolapso genital y enfermedades afines.

El $33,7 \%$ de nuestras pacientes presentó cervicitis crónica, entidad aceptada como la más común dentro de la práctica ginecológica; la inci-

\section{CUADRO NN 7}

CLIMATERIO

PATOLOGIA GINECOLOGICA CONCOMITANTE

\begin{tabular}{lcc}
\hline 1 - Trastornos de la Estática & No Casos & Porcentaje \\
\hline Uretrocistocele & 46 & $57,5 \%$ \\
Rectocele & 40 & $50,0 \%$ \\
Desgarro Perineal & 13 & $16,2 \%$ \\
Incontinencia de Esfuerzo & 8 & $10,0 \%$ \\
Retroversoflexión Uterina & 6 & $7,5 \%$ \\
Prolapso de 3er. Grado & 2 & $2,5 \%$ \\
\hline
\end{tabular}

\section{CUADRO № 7 (Continuación)}

CLIMATERIO

PATOLOGIA GINECOLOGICA CONCOMITANTE

\begin{tabular}{|c|c|c|c|c|}
\hline 2 - Procesos Inflamatorios & & & No Casos & Porcentaje \\
\hline Vaginitis & & & 39 & $48,7 \%$ \\
\hline Cervicitis Crónica & & & 27 & $33,7 \%$ \\
\hline C. Albicans & 20 & $51,2 \%$ & & \\
\hline Vaginalis $T$ & 14 & $35,8 \%$ & & \\
\hline N. Gonorrheae & 2 & $5,1 \%$ & & \\
\hline Inespecífica & 2 & $5,1 \%$ & & \\
\hline Atrófica & 1 & $2,5 \%$ & & \\
\hline Inflamación Pélvica Crónica & & & 4 & $5,0 \%$ \\
\hline Parametritis & & & 2 & $2,5 \%$ \\
\hline Ooforitis & & & 1 & $1,2 \%$ \\
\hline
\end{tabular}




\section{CUADRO N: 7 (Continuación) \\ CLIMATERIO \\ PATOLOGIA GINECOLOGICA CONCOMITANTE}

\begin{tabular}{lrr}
\hline 3 - Enfermedades Neoplásicas & N $^{\mathbf{0}}$ Casos & Porcentaje \\
\hline Fibromiomatosis uterina & 12 & $15,0 \%$ \\
Pólipo cervical & 4 & $5,0 \%$ \\
Displasia cervical & 2 & $2,5 \%$ \\
Carcinoma de Cérvix & 2 & $2,5 \%$ \\
Quiste de Bartholin & 1 & $1,2 \%$ \\
\hline
\end{tabular}

\section{CUADRO № 7 (Continuación)}

CLIMATERIO

PATOLOGIA GINECOLOGICA CONCOMITANTE

\begin{tabular}{lcc}
\hline 4 - Otras Enfermedades & $\mathbf{N}^{\mathbf{0}}$ Casos & Porcentaje \\
\hline Enfermedad fibroquística del seno & 3 & $3,7 \%$ \\
Atrofia genital & 3 & $3,7 \%$ \\
Metaplasia escamosa endocervical & 3 & $3,7 \%$ \\
Adenomiosis & 3 & $3,7 \%$ \\
Hiperplasia endometrial simple & 2 & $2,5 \%$ \\
Hiperplasia glándulo-quística & 1 & $1,2 \%$ \\
Hipertrofia del clítoris & 1 & $1,2 \%$ \\
Várices vaginales & 1 & $1,2 \%$ \\
Esclerosis ovárica & 1 & $1,2 \%$ \\
Papiloma intraductal & 1 & $1,2 \%$ \\
\hline
\end{tabular}

dencia extraordinariamente alta de infecciones vaginales cuya etiología discriminamos en el Cuadro 6 , se puede explicar fuera de los factores socioeconómicos (promiscuidad sexual etc.), por las alteraciones en el mecanismo de autodepuración vaginal con las consecuentes modificaciones del $\mathrm{Ph}$ debidas a la falta progresiva del estímulo estrogénico.

Las enfermedades de tipo neoplásico tanto benignas como malignas, representaron un dato global del $26,2 \%$, del cual la mayor parte (15\%) correspondió a fibromatosis, cifra ligeramente inferior a la aceptada para mujeres por encima de los 35 años, pero anotando que en su mayoría estas neoplasias eran asintomáticas y su diagnóstico fue hallazgo de examen. El 2,5\% correspondió a carcinoma de cérvix, hecho que nos llama la atención hacia la necesidad del cuidadoso examen ginecológico complementado con la pesquisa citológica en el grupo de pacientes de estas edades, en el cual es mayor la frecuencia del carcinoma cérvico-uterino; nos cabe añadir el hallazgo de lesiones de tipo "neoplasia cervical intraepitelial" en la fase evolutiva de displasia $(2,5 \%)$.

\section{Cuadro sintomático del climaterio}

Consideramos de gran importancia la valoración cuidadosa de los síntomas que aparecen en esta época de la vida, debido a que existe la tendencia de atribuirlos al climaterio, 
basándose exclusivamente en la edad cronológica, hecho que nos puede conducir a penosos errores. Análogamente debemos evitar el considerar estas manifestaciones que acompañan a la "edad crítica", como de importancia menor y escasamente dignas de atención. Conviene recordar que ninguna mujer de longevidad normal escapa al climaterio; son pocas sin embargo las que presentan síntomas suficientes para obligarlas a acudir al médico. Se estima en general que alrededor del $25 \%$ de las mujeres en edad menopáusica consultan por molestias que guardan relación directa con el climaterio, o que parecen guardarla. Se piensa que el cambio de vida parece ser más crítico en las mujeres que viven en las grandes ciudades, que tienen que combatir la agitación y el stress de la vida moderna, que en las de las comunidades pequeñas y el campo, donde la vida es más sencilla y donde muy pocas encuentran molesta esta etapa (24).

Hemos clasificado arbitrariamente y con miras a la ordenación de este trabajo, la sintomatología, en tres grupos que analizaremos a continuación:

\section{A) - Síntomas de orden general}

\section{CUADRO $\cdot \mathbf{N} \div 8$ \\ CLI M ATER IO}

SINTOMAS GENERALES.

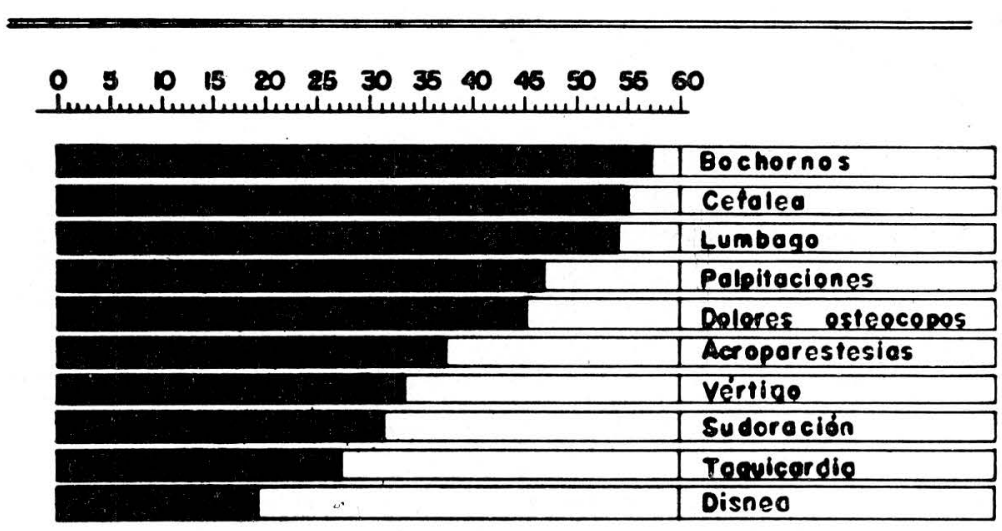

Clásicamente se aceptan como los síntomas más típicos del climaterio, en la esfera general, las oleadas de calor o bochornos, sudores, cefalea, vértigo, dolores osteo-articulares, acroparestesias, etc.

Reynolds (14) describe el "bochorno menopáusico" de la siguiente manera: "Se acompaña de un nota- ble aumento de la cantidad de sangre en las zonas de la piel afectas por el rubor. Ello causa elvación de la temperatura cutánea y sudoración. Cuando el sudor se evapora aparece vasoconstricción".

También afirma que la carencia de esteroides sexuales aumenta la irritabilidad de los vasos sanguíneos cu- 
táneos sobre todo en las áreas del rubor; opina que el mecanismo del rubor menopáusico probablemente dependa de los centros termoreguladores en el hipotálamo. Se ha supuesto además, que el sistema nervioso autónomo se sensibiliza por los estrógenos y que el equilibrio entre el diencéfalo y el sistema órgano-vegetativo queda condicionado en cierta medida por el sostén hormonal. Albright (16) apoya la teoría de que la intensidad de estas manifestaciones guarda relación con la concentración de gonadotropinas en sangre y orina, teoría esta que se dio en llamar "del exceso de gonadotropina". Respecto a este planteamiento se han hecho algunas objeciones que no son obligadamente valederas v.gr. mujeres asintomáticas menopáusicas con alto tenor de gonadotropinas, el síndrome de Turner, la insuficiencia gonadal prepuberal y el síndrome de Klinefelter, los cuales se acompañan de concentraciones igualmente altas sin síntomas menopáusicos. Una observación reciente apoya a los que de esta forma piensan, como es la administración a mujeres de citrato de clomifeno lo que determina excreción de gonadotropinas en concentraciones características de la postmenopausia y experimentan simultáneamente bochornos. Podemos añadir que en favor de la teoría de "carencia de estrógenos" existen los hechos de que no haya relación entre la gravedad de los síntomas y la concentración de gonadotropina, y la eficacia de la estrogenoterapia en dosis que no disminuyen notablemente la producción gonadotrópica.

Con el transcurso de los años y por consiguiente al envejecer, algunas mujeres presentan modificaciones posturales que guardan relación con la debilidad y la relajación de los músculos del dorso. Se presen- tan modificaciones articulares que no son constantes y cuya etiología se puede encontrar en causas metabólicas, traumáticas, nutricionales 0 infecciosas; las artralgias son 5 veces más frecuentes en las mujeres menopáusicas que en los varones de igual edad; los cartílagos articulares presentan erosión no inflamatoria, los intervertebrales infiltración de tejido conectivo que se acompaña en algunos casos de necrosis y calcificación. A menudo se observan espolones osteofíticos en las inserciones ligamentosas.

Al tratar de analizar el síntoma cefalea, manifestación de por sí compleja, de muy variada etiología y aun más difícil valoración, el cual hemos hallado en $68,7 \%$ de nuestra casuística, creemos que además de factores psicológicos y emocionales, se pueden añadir posibles modificaciones cerebrales a nivel de concentración hídrica e hipercolesterolemia con depósitos ateromatosos en vasos cerebrales y la consecuente modificación de la irrigación encefálica (4).

\section{B ) - Síntomas relacionados con el aparato genital \\ CUADRO N: 9 \\ CLIMATERIO \\ SINTOMAS GINECOLOGICOS}

\begin{tabular}{|c|c|c|c|}
\hline Síntomas & No & Casos & Porcentajes \\
\hline Flujo & & 54 & $67,5 \%$ \\
\hline Dolor Pélvico & & 48 & $60,0 \%$ \\
\hline Prurito Vulvovaginal & & 44 & $55,0 \%$ \\
\hline Amenorrea & & 32 & $40,0 \%$ \\
\hline Trastorno Urinario & & 30 & $37,5 \%$ \\
\hline Dispareunia & & 25 & $31,2 \%$ \\
\hline Hipermenorrea & & 23 & $28,7 \%$ \\
\hline Dismenorrea & & 23 & $27,7 \%$ \\
\hline Polimenorrea & & 14 & $17,5 \%$ \\
\hline Metrorragia & & 9 & $11,2 \%$ \\
\hline Sinusiorragia & & 7 & $8,7 \%$ \\
\hline Hipomenorrea & & 7 & $8,7 \%$ \\
\hline Oligomenorrea & & 5 & $6,2 \%$ \\
\hline Sangrado Intermenstrual & & 5 & $6,2 \%$ \\
\hline Espaniomenorrea & & 4 & $5,0 \%$ \\
\hline
\end{tabular}


La impresión general es que el comienzo de la menopausia es más tardío en la actualidad a consecuencia probablemente de la mejor salud y nutrición. No puede prevenirse con certeza el tipo menstrual en los últimos años reproductores. Existe un grupo de mujeres en las cuales, los períodos cesan bruscamente y no reaparece; un grupo intermedio, en las cuales existen intervalos breves y largos entre los períodos. Esta irregularidad puede durar uno, dos o más años. Dichos ciclos raramente son ovulatorios y resultan de aumentos y disminuciones en la producción de estrógenos. Un tercer grupo presenta grandes irregularidades menstruales; los episodios hemorrágicos generalmente duran más tiempo y un período puede ser seguido de otro, en un breve lapso. Estos episodios hemorrágicos nunca deben considerarse como de origen fisiológico, debido a que se corre el riesgo de pasar desapercibido un cáncer del cuerpo uterino, siendo de suma importancia insistir en estos casos en el raspado uterino que permite un diagnóstico en el $95 \%$ de los casos, ya que la citología para los neos del cuerpo uterino solamente es afectiva en aproximadamente el $50 \%(17,46$, $40,38,32$ ).

En algunas ocasiones, las más raras, la ovulación persiste hasta el momento mismo en que termina la vida menistrual; el cese de estas dos funciones no es necesariamente sincrónico y por lo tanto, los últimos ciclos son de tipo anovulatorio.

\section{C) - Síntomas psicógenos} rica.

Psicodinámica de la edad climaté-

Define el término climaterio un largo período de inestabilidad humoral, por el cual la mujer debe atravesar antes de adquirir una nueva forma de serenidad. Este trayecto es incierto. Solo el $20 \%$ de las mujeres menopáusicas lo transcurren silenciosamente; en la mayoría corresponde a la falsa idea que de dicho período tiene la mujer del siglo $X X$. Mal informada, se alarma engañosamente $y$ equivocada, se refugia en la esperanza excesiva de las virtudes ilusorias de la endocrinoterapia. Parece ser que la menopausia es un fantasma que no ha adquirido el derecho de ser citado más que por la acción creadora de la imaginación y del miedo. Gilbert Dreyfus (18) dice que "cada mujer vive la menopausia a su manera", y Michel-Wolfromm (19) añade que "cada mujer tiene la menopausia que se merece".

Existen tres clases de manifestaciones: A) Trastornos emocionales que aparecen en esta época de la vida, sin que se hubieran observado en épocas anteriores; B) Exacerbación de tendencias neuróticas ya existentes, y C) Psicosis de diversos tipos (el más frecuente, la melancolía involutiva). Muy controvertido es el tema sobre el papel respectivo de la alteración endocrina y de la personalidad anterior, como fenómenos causales de los diversos síntomas. Autores hay que los atribuyen únicamente a causas psicológicas, las cuales pueden tener su origen en la inestabilidad del sistema nervioso vegetativo y en la incapacidad para adaptarse a los esfuerzos y tensiones emocionales; de la misma forma, los que presentan como causales la ansiedad derivada del concepto que tiene la paciente de sí misma como ser humano, la tendencia hacia la masculinidad (la cual pudiera haber estado anteriormente enmascarada por represión o sublimación), la "mortificación narcisista" debida a la pérdida de lo ganado en la pubertad, el cansancio de 
la lucha, la inestabilidad emocional, etc.

Por otra parte, no nos es posible ignorar las intensas modificaciones fisiológicas producidas en los diversos tejidos del cuerpo a consecuencia de la privación de estrógenos, modificaciones que a su vez permiten la aparición de reacciones emocionales de cierta importancia ante estímulos subliminales. En definitiva, la época climatérica suele ser de profundos conflictos emocionales, consecuencia de situaciones muy variadas que van a influir en mayor o menor cuantía sobre mujeres que anteriormente se habían adaptado perfectamente a los conflictos de la vida, o por el contrario, a aquellas personalidades emocionalmente inmaduras e inestables que habían dejado traducir desde anteriormente sus rasgos neuróticos (20).

"Femos de considerar los siguientes hechos que conllevan implicaciones psicológicas: la pérdida de la capacidad reproductiva invariablemente asociada con el establecimiento de la menopausia, puede conducir a la aparición de sentimientos de castración y de inutilidad; por otra parte, la aparición de la amenorrea, puede exacerbar el temor consciente 0 inconsciente al embarazo; las mujeres en edad climatérica tienen frecuentemente una noción exagerada del envejecimiento, debido a que su estado fisiológico hace que aparezcan estos pensamientos en forma súbita, de manera que surgen aprensiones y temores innecesarios sobre ellas mismas, el medio en que viven, sus relaciones con la familia y los amigos; a lo antedicho se deben añadir los conceptos equivocados, las fantasías y fobias derivadas del folklore, que se suceden de generación en generación; se pueden presentar preocupa- ciones que relacionan el cambio de vida con la obesidad, la locura y el cáncer; las desaveniencias matrimoniales como problema crónico se pueden intensificar; la perpetuación cultural de conceptos errados acerca de la función sexual, puede derivar en temores a la pérdida de la función sexual y de la líbido; se llegan a experimentar sentimientos culposos, remordimientos o incapacidad, debidos a fallas presentadas en los planes elaborados para los hijos; sentimientos de inutilidad creciente cuando se rompe la unidad del hogar a consecuencia de los deseos de los hijos de desarrollar su propia vida. Trátase pues, de un período de tensiones que predisponen a crisis de ansiedad, frustración, humor cambiante, intranquilidad emocional y depresión reaccional; en casos extremos dichas tensiones, tratándose de mujeres apenas compensadas, pueden desencadenar psicosis que justifican el diagnóstico clínico de melancolía involutiva.

Dentro de nuestro grupo notamos una incidencia muy alta de síntomas relacionados con las alteraciones del humor o el estado de ánimo, entre las cuales y muy frecuentemente asociadas encontramos la irritabilidad $(62,5 \%)$, la ansiedad $(50 \%)$ y la inestabilidad emocional $(41,2 \%)$. Los estados depresivos estuvieron colocados en nivel inferior $(31,2 \%)$, lo cual difiere de otras opiniones que consideran este tipo de distimia como el de más frecuente aparición; por lo general fueron de intensidad leve a moderada, y de carácter reactivo, sin encontrar ningún caso que se pudiera encuadrar dentro del estado psicótico. Los trastornos del instinto sexual se caracterizaron en su mayor parte por tendencia a la disminución $(46,2 \%)$, lo cual puede interpretarse en ocasiones como una adaptación feliz a un estado de he- 
cho muchas veces compensado por una sublimación; este descenso del potencial erótico constituye a veces una gracia para las abandonadas y en otros casos una frigidez antigua bien tolerada se transforma en una fuente de angustia. Cuanto más raro ha sido el placer de la comunión física, más vivo es el miedo de la soledad. La intensificación del instinto sexual la encontramos en muy pocos casos $(5 \%)$, sin acercarse a los extremos descritos bajo la forma de erotomanía. Las diversas fobias señaladas en nuestro cuadro nos muestran, como es aceptado en general, que afectan a variadas situaciones tales como el temor al cáncer, pero incidiendo especialmente sobre un objeto genital (temor a perder la atracción, a la obesidad, a perder la líbido, al embarazo, a las enfermedades venéreas, etc.). Consideramos que el nivel cultural de la paciente, las informaciones pseudo-científicas de periódicos y revistas, intercomunicación de creencias erróneas en reuniones sociales, son hechos que contribuyen a intensificar la aparición de fobias y temores.

\section{CUADRO NN 10}

\section{CLIMATERIO SINTOMAS SICOGENOS}

\begin{tabular}{lcc}
\hline Síntomas & No Casos & Porcentajes \\
\hline Irritabilidad & 50 & $62,5 \%$ \\
Ansiedad & 40 & $50,0 \%$ \\
Disminución de la líbido & 37 & $46,2 \%$ \\
Inestabilidad Emocional & 33 & $41,2 \%$ \\
Insomnio & 30 & $37,5 \%$ \\
Depresión & 25 & $31,2 \%$ \\
Temor al Cáncer & 20 & $25,0 \%$ \\
Temor al Embarazo & 17 & $21,2 \%$ \\
Temor a la Locura & 12 & $15,0 \%$ \\
Agresividad & 7 & $7,5 \%$ \\
Temor a la Obesidad & 5 & $6,2 \%$ \\
Exaltación de la líbido & 4 & $5,0 \%$ \\
Temor a perder la líbido & 3 & $3,7 \%$ \\
Temor a perder la atracción & 1 & $1,2 \%$ \\
Temor a ser considerada inútil 1 & $1,2 \%$ \\
\hline
\end{tabular}

En fin, creemos como McCandless (21), que el condicionamiento cultural y la modificación esperada en el estado de vida siguen siendo los factores más importantes para comprender los problemas emocionales que acompañan al climaterio.

\section{Estudio endocrinológico del Climaterio}

\section{Función Hipofisiaria.}

Desde las investigaciones de Fluhmann se sabe que el suero de mujeres menopáusicas y de las ovariectomizadas posee concentraciones elevadas de gonadotropinas. Con posterioridad, Zondeck demostró abundante gonadotropinuria en las postmenopáusicas. Ensayos posteriores que tratan de dilucidar el carácter cualitativo de la gonadotropinuria postmenopáusica han comprobado que la potencia gonadotrópica de la hipófisis de estas mujeres es unas diez veces mayor que la de las premenopáusicas, y además, la valoración del tejido hipofisiario ha revelado un complejo que posee intensa actividad de FSH y signos patentes de actividad LH. En la actualidad se acepta que al fallar el mecanismo regulador de retroalimentación, se determina un aumento compensatorio en la actividad de la adenohipófisis, que se traduce por la mayor concentración de gonadotropinas en la sangre $y$ el consiguiente incremento de su excreción urinaria (39). La hipergonadotropinuria persiste hasta los $60 \circ 70$ años, existiendo variaciones de tipo individual; a partir de esta edad se aprecia una notable disminución en la excreción gonadotrópica, lo cual puede indicar la menor capacidad del organismo para su elaboración por la senectud tisular generalizada. Se ha observado que la producción gonadotropa guarda relación con el tiempo transcurrido desde la 
menopausia, así por ejemplo, cuando han pasado menos de 25 años la excreción media de gonadotropina es bastante mayor que cuando han transcurrido más de 25. La determinación de las hormonas gonadotropas de origen hipofisiario se realiza empleando suero u orina (44-49); cuando se practican titulaciones en orina, es indispensable recolectarla durante 24 a 48 horas y someterla a procesos de desintoxicación y concentración. En el momento, solo es dable lograr determinaciones cuantitativas, mediante la prueba del peso de útero de ratones para la $\mathrm{FSH}$, y por medio de la prueba del lóbulo ventral de la próstata para la $\mathrm{LH}_{\text {; la }}$ cantidad de FSH se calcula por diferencai entre las gonadotropinas totales y la LH. Como valores de eliminación diaria total para las mujeres en la época del climaterio y las ooforectomizadas, se dan las cifras de 50 a 200 unidades ratón. Recientemente ha sido posible determinar cuantitativamente las gonadotropinas hipofisiarias con la ayuda de datos inmunológicos.

La complejidad para la realización de estas determinaciones, que requieren procedimientos de laboratorio especializados, las han puesto fuera de nuestro alcance en este trabajo y por ello hemos tratado de valorar globalmente la función hipofisiaria de la climatérica a través de la respuesta de los órganos efectores.

Cualquier estudio tendiente a valorar la influencia de los esteroides en la producción de gonadotropinas, debe tomar en cuenta las grandes variaciones diarias en su excreción. Es aceptado que los estrógenos en dosis adecuadas disminuyen con rapidez la excreción de gonadotropinas, existiendo sin embargo algunas substancias de acción estrogénica que es- timulan su producción si se administran a baja dosis; por el contrario, dosis mayores de estas mismas substancias pueden suprimir su producción. Smith y Albert comprobaron que la administración diaria de 0.1 mg. de estilbestrol aumenta la excreción gonadotrópica en las ooforectomizadas, y dosis diarias de $1 \mathrm{mg}$. - más la disminuyen de manera importante. La metiltestosterona a dosis de 5 a 10 mgs. día, modifica poco la excreción gonadotropa; en cambio, el 17 alfa etil 19 nortestosterona a 20 mgs. día la disminuye de manera importante. La mayor parte de las pruebas indican el efecto escaso o nulo en lo que se refiere a la gonadotropinuria, de la progesterona; existen sin embargo algunas progestinas tales como la noretindrona $y$ el noretinodrel, que poseen efecto supresor intenso en la secreción de gonadotropinas.

\section{2․ Función Tiroidea.}

Es concepto conocido que en la fase climatérica de la vida, existe una hiperactividad generalizada de la adenohipófisis; este fenómeno lleva consigo no solamente un aumento en la secreción de hormonas gonadotropas sino también, de otras hormonas trópicas entre ellas la TSH y el ACTH. Este concepto se apoya en pruebas no muy notables, pero en algunas mujeres es patente la hiperactividad tiroidea en etapa incipiente del climaterio, siendo en las demás norma!.

Utilizamos como prueba de función tiroidea la del yodo ligado a la proteína en un total de 14 pacientes. El $64,28 \%$ se encontraron dentro de las cifras consideradas normales ( 4 a 8 gammas), el $28,57 \%$ en cifras que oscilaron entre 11 y 19 gammas y solo el 7,14\% ( 1 caso) tuvo un valor subnormal. Destacamos que en 
CUADRO NOII

CLIMATERIO

\section{VALORES DEL PBI EN 14 PACIEMTES}

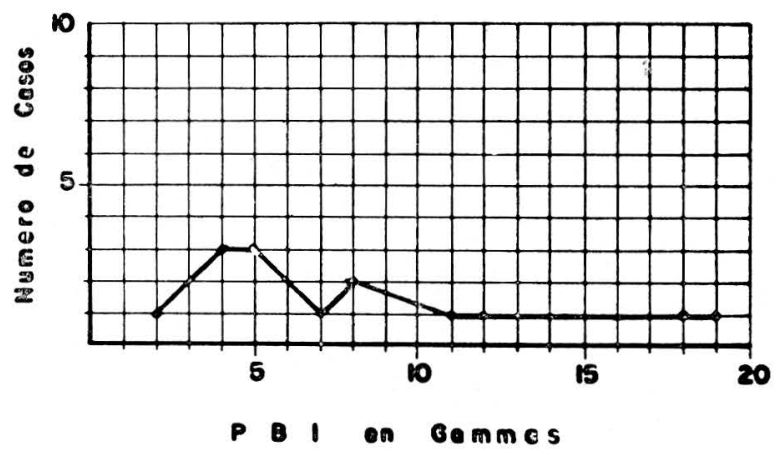

el grupo de pacientes con cifras elevadas, no encontramos ninguna que presentara manifestaciones clínicas de hipertiroidismo franco y consideramos que algunos de estos resultados pudieran corresponder a ligero aumento de la función tiroidea y otros a las posibles causas de error de la prueba en sí como ingestión de antiamibianos, utilización de medios yodados de contraste, medicación tiroidea previa o defecto en el procesamiento de las muestras por transporte, toma, etc.

\section{3․ Función Suprarrenal.}

Se ha sugerido que al suspenderse la función ovárica hay un aumento compensador de la función suprarrenal; sin embargo, no hay pruebas adecuadas de que la menopausia fisiológica o la ovariectomía modifiquen de manera importante la concentración de 17 Cetosteroides (44). La mayor parte de estos metabolitos proceden en la mujer del metabolismo de los andrógenos producidos en la corteza suprarrenal, y en menor cuantía de la degradación del cortisol; un reducido porcentaje tiene su origen en las células hiliares del ovario. Mediante fraccionamiento se los puede dividir en 8 grupos, de los cuales las fracciones 4 a y 5a proceden según Dingemande (25) probablemente del ovario.

Al cesar la función ovárica se cree que se produce inicialmente una insuficiencia cortical que afecta principalmente la zona androgénica por la disminución de la hormona luteotropa; simultáneamente se encuentra una hiperfunción gonadotrópica de la FSH, y del ACTH, que tratan de compensar la falla gonadal.

Debido a que los 17 cetosteroides provienen en su mayoría de los precursores suprarrenales, es de suponer que la concentración variable que de ellos se encuentra en las diversas edades, refleja en cierta medida la actividad variable de la glándula. 
Para evaluar la función córticosuprarrenal nosotros efectuamos dosificación de 17 cetosteroides en orina de 24 horas a 50 pacientes, siguien- do la técnica de Drekter (50), cuyos valores normales para la edad y sexo que investigamos oscilan entre 4 y 8 mgs. $/ 24$ horas.

CUADRO NO12

CLIMATERIO

17 CETOSTEROIDES URINARIOS EN SO PACIENTES.

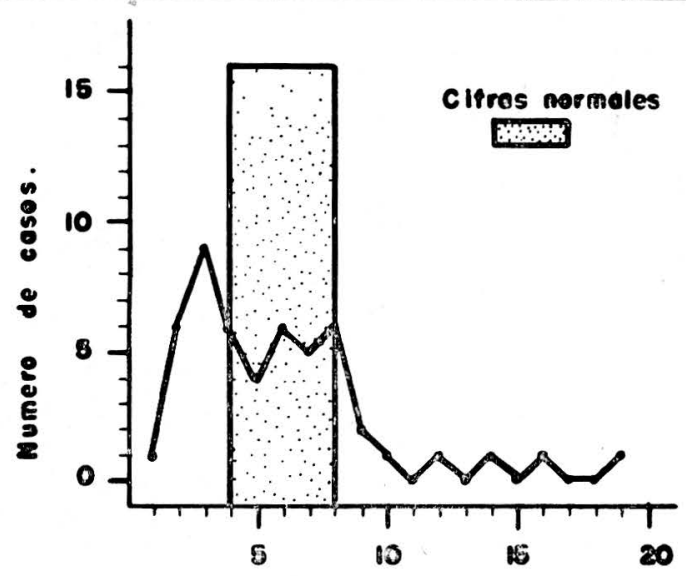

17. Cerosicroles en mesta moros.

En el Cuadro, vemos que el $54 \%$ se sitúa dentro de la zona de normalidad, el $14 \%$ ( 7 casos) por encima de dicha zona, y el $32 \%$ ( 16 casos) en cifras por debajo de lo normal. Queremos aclarar que nuestro caso N: 9 en un primer estudio arrojó cifras de 19,3 mgs. y en una segunda valoración se mostró como normal (6 mgs.).

El análisis de conjunto nos demuestra que la excreción de 17 cetosteroides durante el climaterio puede presentar oscilaciones, pero que en la gran mayoría de los casos la función córticosuprarrenal no se modifica de manera importante. Existen variadas situaciones que pueden modificar de manera considerable los valores de excreción urinaria, tales como el agotamiento, la desnutrición, el trabajo físico, las enfermedades crónicas, las intervenciones quirúrgicas, administración de drogas (corticoides, andrógenos, vitamina C), las enfermedades mentales, y han de tenerse muy en cuenta además, no solamente los síndromes adrenogenitales y los tumores funcionantes, sino también las notables oscilaciones diurnas y nocturnas de su eliminación en personas sanas, correspondiendo un máximo de excreción en las primeras horas de la mañana.

\section{Función Ovárica.}

En el período climatérico la función ovárica en la mayoría de los casos, disminuye en forma gradual; este concepto de trancisión progresi- 
va de ciclos ovulatorios hasta la inactividad ovárica completa, está sustentado por varios hechos a saber: a) Las alteraciones menstruales que suelen indicar una función ovárica anovulatoria pueden preceder en meses o años a la insuficiencia ovárica completa; b) Debido a este estado progresivo de cosas, existe un porcentaje relativamente reducido con síntomas menopáusicos graves; c) Por el contrario la mujer ooforectomizada presenta síntomas climatéricos de aparición más rápida y en general más ruidosa, que los que acompañan a la menopausia fisiológica $y, d$ ) Los extendidos vaginales a menudo descubren estimulación estrogénica persistente bastante tiempo después de establecida la menopausia $(31,33)$.

La base endocrina fundamental de la declinación ovárica se establece principalmente en primer lugar por la deficiencia de estrógenos detectada por medio de la citología o la disminución de la excreción urinaria de los productos finales de su metabolismo, y en segundo lugar, por la producción excesiva de gonadotropinas. Está demostrado que aunque la concentración de estrógenos en la mujer menopáusica suele ser bastante menor que en la que aún menstrúa, estos siguen produciéndose; se ha comprobado además que en la sangre y orina de mujeres postmenopáusicas y en las ovariectomizadas, hay estrógenos. Estos hechos han motivado la investigación del origen de estos esteroides sexuales; se ha sugerido que el ovario postmenopáusico conserva la capacidad de tener actividad endocrina, basándose en la observación por medio de la citología del . mejor estado estrogénico de aquellas mujeres que se encuentran en menopausia fisiológica en relación con las ovariectomizadas. Parece indiscutible que hay producción córticosuprarrenal de estrógenos, teniéndose como elementos de juicio, que la extirpación de los ovarios en la postmenopausia no modifica las cifras de estrógenos, pero la adrenalectomía en la castrada, produce disminución intensa e inmediata de ellos.

Como pruebas de la función gonaclal hemos utilizado la citología funcional por el método de Papanicolaula prueba funcional descrita por Cardona (27) (valoración del FSH por medio de la citología), la biopsia endometrial y los estudios histoquímicos del endometrio.

\section{A) Estudio Cito-Hormonal.}

Se practicaron en la totalidad de las 80 pacientes estudiadas tomas citológicas vaginales, previa eliminación de factores infecciosos locales que pudieran distorsionar los resultados. El 21,25\% (17) demostraron un franco hiperestrogenismo; el $70 \%$ (56), moderado a discreto hipoestrogenismo, y el $7,85 \%$ (7) frotis de tipo atrófico. Cotejando los datos citológicos con las modificaciones del flujo catamenial observamos que todas aquellas pacientes con alteraciones de tipo hemorrágico presentaban frotis hiperestrogénicos. Del análisis de los resultados podemos concluir como de mayor incidencia en esta época de transición el hipoestrogenismo discreto seguido de los estados hiperestrogénicos no infrecuentes en este momento de la vida, determinados por la actividad monofásica del ovario, y un muy reducido grupo de estados francamente atróficos explicados principalmente por acción de la castración quirúrgica.

B) Valoración del FSH por medio de la citología (27). 
Se basa esta prueba en el estado refractario ovárico al estímulo gonadotrópico. Empleamos gonadotropina sérica a la dosis de 5.000 U. vía intramuscular en aplicación única, tomando citología previa y muestras seriadas del día 2 al 6 postaplicación. Se estudiaron en esta forma 25 pacientes, lográndose respuesta positiva (desviación hacia la derecha del índice de maduración citológica) en 1 sola de ellas, la cual correspondía al caso de menopausia precoz ocasionada por panhipopituitarismo. En las 24 restantes, concluímos que el estado hipoestrogénico previo, tenía como fundamento la hipofunción gonadal.

\section{Estudio Morfológico \\ e Histoquímico del Endometrio}

Estudiamos 51 biopsias obtenidas con la Cureta de Novak durante los períodos proliferativo, secretor inicial y avanzado, durante el período menstrual o durante la época de amenorrea. Se recibió el material en alcohol absoluto y allí permaneció por un período no inferior a 24 horas. Se procesó según la técnica usual de inclusión en parafina; fue cortado a 5 micras y coloreado con hematoxilina eosina para el estudio morfológico; con carmín de Best y PAS para el estudio del glicógeno; con Alcian Blue para mucopolisacáridos ácidos y, según la técnica de Gomori para Fosfatasas Alcalinas.

Hallazgos: Un buen número de casos, "39", fueron considerados como normales en cuanto a su morfología y actividad enzimática. Otros, 5, mostraron algunos cambios de maduración irregular y, 5 fueron hiperestrogénicos; 1 correspondió a un endometrio secretor de un ciclo corto $y$ otro también secretor, a un ciclo largo.

\section{CUADRO № 13 \\ CLIMATERIO \\ ESTUDIO MORFOLOGICO E HISTOQUIMICO \\ DE 51 CASOS}

\begin{tabular}{|c|c|c|}
\hline Tipo de Endometrio & No & de Casos \\
\hline $\begin{array}{l}\text { Fase proliferativa } \\
\text { Fase secretora } \\
\text { Fase menstrual } \\
\text { Endometrio atrófico } \\
\text { Mestras insuficientes } \\
\text { * Hiperestrogénicos } \\
\text { * Maduración irregular }\end{array}$ & $\begin{array}{l}5 \\
5\end{array}$ & $\begin{array}{l}12^{*} \\
14^{* *} \\
12 \\
10 \\
3\end{array}$ \\
\hline
\end{tabular}

La actividad glicogénica se hizo presente desde la fase intermedia siendo notoria su positividad en la secreción glandular luminal durante la fase secretora avanzada de cuarta semana.

Las fosfatasas alcalinas fueron positivas en el epitelio glandular durante la fase proliferativa y en la secreción durante la tercera semana, notándose una disminución paulatina en las glándulas a medida que avanza el ciclo para hacerse positiva en este momento en el endotelio vascular.

Los mucopolisacáridos fueron positivos en el epitelio glandular durante la fase proliferativa y en la secreción glandular durante la cuarta semana. Es de anotar que esta reacción fue de utilidad para la distinción entre la fase menstrual propiamente dicha y la fase pre-menstrual ya que durante los días de sangrado su positividad es muy escasa, prácticamente ha desaparecido, posiblemente porque se han eliminado rápidamente.

Las fosfatasas alcalinas fueron útiles para demostrar en algunos casos una disinergia glándulo secretora especialmente en algunos casos de hiperplasia estrogénica. 
El estudio enzimático puso en evidencia la disminución progresiva de la función en algunos casos donde siendo la morfología de un período secretor avanzado, la actividad enzimática fue muy pobre.

Durante la fase menopáusica se hace notoria la falta de actividad glandular, su epitelio se hace más bajo, la seudoestratificación y las mitosis van desapareciendo, se produce un relajamiento glandular en algunos casos y aparición de formaciones quísticas.

El estroma decrece progresivamente, sus células son de núcleos fusiformes cada vez más pequeño.

Un hecho que llamó la atención fue la presencia del tejido endometrial de aspecto hiperestrogénico con poca o casi ninguna actividad histoquímica, hecho evidenciado especialmente con la falta de actividad de fosfatasas alcalinas a nivel epitelial. Estos casos los hemos considerado como endometrios de morfología seudo-hiperfuncionante, pues en realidad hay un cese de las funciones enzimáticas, como si estas substancias reflejaran el mantenimiento del trofismo glándulo-estromal y al venir la disminución hormonal se relajaran o viniera un desconcierto traducido por la dilatación glandular y cierto grado de multiplicación celular que trataba de suplir con aumento de sus elementos celulares la falia hormono-enzimática; algo que hemos querido comparar, guardando las debidas proporciones, al caso de la falla de hormonas estimulantes del tiroides que se traducen por un crecimiento de la glándula; hipertrofia que en realidad lo que revela es un estado hipofuncionante. El trofismo glandular permaneció similar al de una fase proliferativa mediana por un buen tiempo en pacientes menopáusicas y en otras no se observó mejoría con el tratamiento.

Se presentó un caso que fue estimulado con terapia mixta (estrógenos-andrógenos de depósito), y cuyo estudio histológico correspondió a una fase secretora prolongada sin la aparición del período menstrual después de los 61 días.

En unos pocos casos el estudio histoquímico permitió ubicar la muestra más correctamente dentro del ciclo endometrial a pesar de lo escaso del material (51, 52, 53).

\section{Tratamiento del Climaterio}

El enfoque terapéutico de la paciente climatérica presenta como aspectos fundamentales: a) Psicoterapia a fin de dar tranquilidad, apoyo y educación. b) Sintomático, con el objeto de ayudar a dominar los síntomas molestos. c) Hormonal, de tipo substitutivo para facilitar los ajustes endocrinos.

Sobre el particular existe el pensamiento de tipo naturalista que nos recuerda al climaterio como un período de transición fisiológica y que por lo tanto no debe recibir tratamiento, a fin de no interferir los fenómenos naturales. Consideramos que una posición como esta no solo llevaría al estancamiento en las investigaciones científicas, sino también conduciría a una actitud nihilista; se debe tener como propósito lógico de la terapéutica facilitar esta etapa transicional con el fin de que la mujer adopte un nuevo papel biológico y social.

\section{A) Psicoterapia.}

Básicamente, el éxito del tratamiento depende en gran parte de la simpatía y comprensión con las que el médico acoja a la paciente; ésta 
debe ser informada de manera sencilla lo que es y lo que no es la menopausia. Hay necesidad de permitirle que exprese con libertad sus conflictos, temores y aprensiones; es importante corregir conceptos equivocados y se debe valorar el grado de su apreciación real, quimérica o exagerada. Hacer que comprenda que el cambio de vida no es el fin, sino el comienzo de una nueva etapa; se la debe inducir a alcanzar con nuevo vigor, metas no logradas con anterioridad y a dar un nuevo impulso a sus actividades en el hogar y la comunidad. No existen en realidad dosis hormonales que reemplacen este tipo de terapia y debido a las muchas dimensiones del problema, el médico debe estar lleno de recursos y abstenerse de creer haber obtenido la solución del problema, con el simple hecho de una prescripción.

Como la implicación terapéutica, creemos que el ginecólogo que aspire a tener buenos resultados en el manejo de este tipo de pacientes, debe saber escuchar sin interrumpir, sin interpretar, y sobre todo, sin sugestionar, ya que estos son requisitos básicos de una encuesta psicosomática; la mujer que necesita ayuda es influíble y sensible a la sugestión; para corresponder y sin querer exagerar a conciencia, responderá sí, a toda pregunta u observación. Según un adagio popular "cada edad tiene sus placeres"; la edad madura ofrece mil recursos a los seres bien dispuestos; múltiples son las alegrías de la madurez; haciéndolas descubrir a la paciente curaremos rápidamente sus molestias.

\section{B) Tratamiento sintomático.}

$A$ veces es útil, para síntomas particularmente molestos, emplear estimulantes, sedantes y tranquilizantes. Se aconsejan en términos generales los agentes farmacológicos más sencillos cuya acción puede predecirse mejor, tales como el fenobarbital, la belladona y el meprobamato. Algunos utilizan en casos de problemas depresivos medicamentos psicoanalépticos del tipo de las anfetaminas, solas o en asociación con barbitúricos; por lo general estos fármacos se prescriben en cursos breves e intermitentes debiendo vigilarse atentamente para suprimirlos en forma paulatina, pues no debemos olvidar el peligro de habituación o dependencia, especialmente en las personalidades psicológicamente predispuestas (43).

C) Hormonoterapia.

En la actualidad el tratamiento médico de la menopausia no ha brindado el beneficio deseado. El sistema utilizado se basa en la administración supletoria hormonal al declinar la producción endógena de esteroides ováricos, y disminuirla lo más rápidamente posible hasta llegar a su supresión, en el momento en que las molestias lo permitan. Sobre este tema, se plantean las más variadas controversias, pues numerosos autores abogan por la substitución hormonal sistemática e indefinida, y otros por el contrario afirman que la mayoría de las menopáusicas no requieren tratamiento endocrino, no resultando posible conciliar estos diversos puntos de vista, por falta de datos concluyentes que reafirmen 0 impugnen cada una de estas posiciones $(30,43,35,22,15,42,34)$.

\section{Estrógenos}

Su uso a la luz de las diferentes opiniones presenta numerosos interrogantes que no dejan de causar profunda inquietud y que en su mayoría no han sido resueltos. Se justifica su utilización profiláctica como 
tónico femenino o con fines rejuvenecedores? Su comprobado efecto favorable sobre la elasticidad de los tejidos, piel y mucosas en particular, en la prevención de la aterosclerosis $y$ osteoporosis, $y$ en el incremento de la actividad mental y física (22), son factores determinantes para su administración sistemática a largo plazo? Son los esteroides sexuales potencialmente cancerígenos, 0 por el contrario, ejercen una acción protectora contra las neoplasias malignas uterinas? Debe ser considerada la menopausia como una enfermedad, en el sentido de estado de deprivación, o por el contrario se trata de una etapa de adaptación fisiológica?

La candidata óptima para el tratamiento substitutivo con estrógenos es la menopáusica a quien se ha practicado histerectomía; el problema de aquella cuyo útero está intacto es difícil. No se encuentra ninguna forma terapéutica que garantice la no aparición de hemorragia provocada por estrógenos; se acepta en general, que es menos probable con dosis bajas (15). Consideramos de gran importancia no subestimar el sangrado iatrogénico, pues a menos de contar con un dato histológico reciente el clínico debe recurrir a todos los medios a su alcance para descartar otras causas determinantes tales como neoplasias $(40,32)$. Antes de iniciar la terapéutica estrogénica hay necesidad de practicar un estudio completo de cada paciente con el fin de poder excluir los procesos patológicos que contraindican su utilización, de la índole de leiomiomas, endometriosis, carcinoma del cérvix, adenocarcinoma endometrial, carcinoma del seno, hiperplasia endometrial adenomatosa e insuficiencia cardíaca congestiva. Creemos que la utilización de la medicación estrogénica pura no es un sistema ideal en el manejo de la paciente climatérica premenopáusica, inclinándonos en ella por la asociación de preparados de estrógeno progesterona combinados, o en sistema secuencial.

Es aconsejable realizar la evaluación de la dosis en función de 3 factores: la tolerancia, la cesación de síntomas, y el índice cariopicnótico de la citología vaginal $(4,33)$.

Existen diversos preparados con acción estrogénica, naturales o sintéticos (sulfato de estrona, etinilestradiol, dienestrol, estilbestrol), cuya escogencia puede basarse en factores tales como el costo del tratamiento, receptividad de la paciente y experiencia personal del médico tratante; al elegir un estrógeno es más importante considerar su potencia que su origen, sin existir pruebas de que difiera de manera substancial la acción de los estrógenos naturales y sintéticos (23). Es concepto unánime, de que han de ser administrados por vía oral, siendo escasas las indicaciones de la vía parenteral; los preparados farmacológicos con estrógenos de acción prolongada (vía parenteral), no tienen ninguna ventaja sobre la vía oral, y sí en cambio los problemas derivados de lo imprevisible de su absorción, la duración de su efecto y la liberación hormonal continua; sus indicaciones estarían limitadas a aquellos raros casos de intolerancia gástrica completa 0 incapacidad psicológica de la paciente para tomar el medicamento.

El régimen para su empleo que parece mostrarse más beneficioso, debido a que evita la congestión mamaria y produce el oleaja fisiológi$\mathrm{CO}$, es el de 21 días de tratamiento y 7 de receso; en caso de que alguna paciente presente molestias muy marcadas durante la supresión conviene acortar el lapso de 7 días, a 5 
- 3. La dosificación debe mantenerse en el nivel mínimo para librar a las pacientes de los síntomas, lo cual suele obtenerse con dosis del orden de 0.625 mgs. de sulfato de estrona, 0.5 mgs. de estilbestrol, 0.2 mgs. de dienestrol y 0.02 mgs. de etinilestradiol por día. En lo referente a la duración de la estrogenoterapia, cada vez se acopian más pruebas de que la vida limitada de la gónada femenina priva a la mujer de una hormona indispensable para la salud y el bienestar; hay quienes creen que la administración esporádica para aliviar los síntomas es un método anticuado y el uso a largo plazo es importante para retardar los fenómenos del envejecimiento muy especialmente en lo que se refiere a la aterosclerosis y sus secuelas. La solución de este problema requiere el juicio del tiempo y la luz de las investigaciones futuras a largo plazo $(22,23)$.

Parece un hecho demostrado que los estrógenos no son cancerígenos; 30 años consecutivos de utilización clínica no han aumentado la incidencia de cáncer en grupos cuidadosamente vigilados. Por el contrario, hay quienes piensan que proteger a la mujer menopáusica contra el carcinoma del cérvix; merece la pena destacar, sobre este particular, los 5 distintos estudios realizados por Pincus y García con un total de 1.422 casos en los cuales solo aparecieron 5 cánceres, cuando estadísticamente la posibilidad era de 96, y los de Schiever Saunders cuando sobre 500 casos seguidos durante 15 años esperaba 30 y no encontró ninguno. Greenblatt evidenció nula incidencia de $\mathrm{Ca}$ de endometrio en un período de 25 años de observación de 292 mujeres.

\section{Gestágenos}

No hay pruebas de que la progesterona desempeñe papel fisiológico en la economía corporal aparte de la reproducción. Recientemente se han sintetizado gestágenos de gran efecto por vía oral; estos difieren entre sí en su mecanismo de acción y en su potencia, pero en cierta forma reproducen parcialmente los efectos de la progesterona. Se derivan de diversos grupos químicos como la progesterona, la testosterona, la 17 hidroxi progesterona, la 19 norprogesterona y la 19 nor testosterona. Por su mecanismo de acción sobre el hipotálamo inhiben la ovulación y pueden ser administrados simultáneamente con los estrógenos o en forma secuencial $(30,43)$.

Pensamos que son de gran utilidad en el climaterio premenopáusico, ya que con ellos, además de lograr una terapéutica substitutiva se le ofrece a la paciente un recurso antifecundante. Conocemos la dificultad en aconsejar a una mujer que comienza a acercarse a la menopausia y a tener ciclos anovulatorios, en relación con la seguridad de que puede tener coitos sin riesgo de quedar embarazada; el uso de las nuevas formas de esteroides anovulatorios durante un tiempo prudencial nos ayuda a brindar protección en este aspecto. Los consideramos también de utilidad en los casos de hiperestrogenismos en esta etapa de la vida y numerosos autores abogan por su administración afirmando que tienen una acción favorable en la prevención de los tumores endometriales.

\section{Andrógenos (28)}

Se puede afirmar categóricamente que con raras excepciones, no hay indicación clara para su empleo exclusivo en la paciente climatérica. Inhiben la función gonadotrópica de la hipófisis y mejoran las oleadas de calor y bochornos; la experiencia comprueba sin embargo que las do- 
sis requeridas para lograr este alivio, son a menudo virilizantes. En casos postovariectomía bilateral efectuada por cáncer mamario o uterino, o endometriosis extensa, puede justificarse su uso de manera prudente y controlada. La metiltestosterona es la más aconsejada a dosis menores de $200 \mathrm{mgs} . / \mathrm{mes}$. No cometamos el error de prescribir endógenos para procesos benignos, a mujeres a quienes la exaltación de la líbido provocada por ellos, puede crearles graves conflictos psicosexuales y ético-religiosos.

\section{Asociación estrógeno-andrógeno}

Debido al efecto anabolizante, a la acción favorecedora en la formación de tejido-osteoide, al restablecimiento o aumento de la líbido, a la euforia y sensación de bienestar que producen las substancias androgénicas, se afirman que al combinarlas con derivados estrogénicos, aumenta la dimensión terapéutica del preparado endocrino. Estas combinaciones tienen efecto sinérgico en lo que se refiere a la supresión hipofisiaria y pueden permitir disminuir las dosis útiles de estrógenos, lo cual simultáneamente disminuye la probabilidad de que ocurra hemorragia estrogénica. Se utilizan en general formas de depósito por vía intramuscular con asociaciones de valerianato o ciclopentilpropionato, y un éster de la testosterona. En la misma forma que ocurre en otros aspectos del tratamiento de la climatérica esta terapia tiene partidarios y antagonistas; existe una renuencia natural a la androgenoterapia en la mujer excepto en sus indicaciones específicas. Se aconsejan especialmente estos preparados cuando se desea obtener un efecto antidepresivo, o en los casos de osteoporosis grave. Existe como seria objeción para su uso prolongado la aparición de los signos de virilización y la posible influencia desfavorable de los andrógenos sobre la acción protectora contra la aterosclerosis descrita para los estrógenos.

Para concluir tenemos la firme convicción de que el tratamiento de la climatérica requiere conocimientos básicos de las relaciones endocrinas en esta etapa vital; conocemos poco el verdadero carácter de la mecánica del envejecimiento y no estamos en posición de impedir o evitar los cambios que produce la edad. La valoración inteligente de los diversos síntomas, nos permitirá diferenciar su origen orgánico o psicosomático; las hormonas no se deben emplear en forma irresponsable y debemos tener muy en cuenta que el propósito de la terapéutica es tratar no la menopausia, sino la paciente, y hacer este período de transición de importancia capital en la vida de la mujer, más fácil, más placentero y más amable.

\section{CUADRO № 14}

\section{CLIMATERIO \\ GRUPOS DE TRATAMIENTO}

I - Testigo: síntomas leves. - sin terapia.

11 - Síntomas marcadoss. leve hipoestrogenismo: Opipramol.

III - Premenopáusicas: síntomas moderados, trastornos menstruales, Mestranol + clormadinona.

IV - Hipoestrogénicas: ciclos largos o amenorrea. Valerianato de estradiol oral.

$V$ - Ooforectomizadas. Dienantatos + benzoato de estradiol IM.

VI - Desnutridas, osteoporosis, hipoestrogenismo severo. Enantato de testosterona + enantato de estradiol IM.

En nuestras pacientes, y según sus manifestaciones clínicas, hemos ela- 
borado 6 tipos de tratamiento, de cuyos resultados y valoración no podemos emitir conceptos en la actualidad, debido al reducido número de pacientes y corto tiempo de control; esto será objeto de una comunicación posterior. (Cuadro N: 14).

Grupo I - Pacientes con síntomas generales vagos y poco intensos, las cuales se encuentran en observación clínica, sin terapia hormonal, ni sedativa.

Grupo II - Pacientes con leve o moderado hipoestrogenismo, síntomas generales y psicoemocionales marcados, a quienes hemos administrado Opipramol a la dosis de mgs. 3 veces por día.

Grupo III - Pacientes en climaterio premenopáusico, con sintomatología general y psicoemocional no muy severas, y trastornos menstruales, sometidas a terapia secuencial, a base de Mestranol (80 microgramos) y Clormadinona (2 mgs.).

Grupo IV - Pacientes con manifestaciones de hipoestrogenismo, en amenorrea o con ciclos largos; sometidas a terapia cíclica de 21 días a base de $2 \mathrm{mgs}$. de valerianato de estradiol por vía oral, seguida por 7 días de descanso.

Grupo V - Pacientes ovariectomizadas por procesos no malignos, que recibieron $15 \mathrm{mgs}$. de dienantato de estradiol y $1 \mathrm{mg}$. de benzoato de estradiol en solución oleosa, con intervalo de 4 a 6 semanas.

Grupo VI - Pacientes con osteoporosis, desnutrición y marcado hipoestrogenismo a las que se administró 150 mgs. de hidrazona del ácido bencílico de enantato de testosterona, 7,5 mgs. de enantato de estradiol y 1 mg. de benzoato de estradiol, en aceite de maíz, en aplicación parenteral cada 4 a 6 semanas.

\section{Conclusiones}

1? El climaterio debe considerarse como un estado deprivativo, que repercute fundamentalmente en todo el organismo. Creemos se debe clasificar en etapas para su mejor estudio y manejo clínico, teniendo como base su principal manifestación, la menopausia.

2. En nuestro medio la menopausia se presenta a la edad promedio de 47 años, llamando la atención acerca de un no escaso porcentaje de pacientes que menstrúan por encima de los 50 años.

3. Hacemos resaltar la alta incidencia de pruebas serológicas positivas, así como el alto índice de osteoporosis presente en nuestras pacientes.

4. Encontramos tendencia hacia la hiperactividad tiroidea en las etapas iniciales del climaterio. No observamos modificaciones significativas en la función córtico-suprarrenal, valorada por la eliminación de 17 cetosteroides urinarios.

5: La función ovárica estudiada por medio de la citología vaginal mostró en la mayoría de los casos leve 0 moderado hipoestrogenismo. Consideramos de utilidad la valoración del FSH por medio de la citología en aquellos medios en que debido a la falta de recursos técnicos, no es posible elaborar dosificaciones de gonadotropinas.

6: Llamamos la atención hacia la cuidadosa pesquisa del cáncer uterino, por ser precisamente esta etapa de la vida la más susceptible para su aparición.

7․ El estudio morfológico, complementado con el histoquímico, es la 
forma más adecuada para valorar el verdadero estado endometrial.

8: El estudio enzimático sirve para evidenciar estados disinérgicos glándulo-secretores, y para detectar precozmente la hipofunción hormonal antes de que los cambios morfológicos sean evidentes.

9: Debido a la importancia demostrada del papel de los estrógenos en diversos aspectos de la economía, especialmente en lo que se refiere al mantenimiento del trofismo genital, del sistema cardiovascular, y la osteogénesis, estamos convencidos del valor de la terapéutica substitutiva a largo plazo en la paciente climatérica; de la misma manera nos hacemos partícipes de la opinión de quienes recomiendan (47) no practicar ooforectomía profiláctica en pacientes sometidas a histerectomía por procesos benignos.

\section{Resumen}

Se estudiaron 80 pacientes en edad climatérica, de acuerdo a una metodología propuesta. Se analizan los resultados teniendo en cuenta la edad de aparición de la menopausia, los antecedentes gineco-obstétricos, las enfermedades generales asociadas y la patología ginecológica concomitante. Se hace un estudio del cuadro sintomático en sus aspectos de orden general, genital y psicosomático. Se efectúa una valoración del estado endocrinológico, basándose en datos citológicos, dosisficaciones hormonales, estudios histopatológicos y bioquímicos (actividad enzimática glicogénica de mucopolisacáridos ácidos y de fosfatasa alcalinas en el endometrio). Se preconiza un enfoque terapéutico múltiple considerando los aspectos psicológicos, sintomáticos y hormonales. Se dan conclusiones.

\section{Summary}

Eighty patients in climacteric age were studied, according to a proposed methodology. Results are analyzed considering the age at the onset of the menopause, the gynecological and obstetrical histority, associate diseases and current gynecological pathology. A study of the symptoms in its general, gynecological and psychosomatic aspects is made. Endocrinological estate is evaluated, based on cytological data, hormone assays, histopathological and histochemical (glicogenic enzymatic activity of mucopolisacharid acid and alkaline phosphatases in the endometrium) studies. A multiple therapeutic approach is reccomended, considering the psychological, symptomatic and hormonal aspects. Conclusions are made.

\section{BIBLIOGRAFIA}

1 NETTER A. et SEBAUN M.: Menopause précoce. Gyn. Obst. 66: 249, 1966.

2 ROGERS J.: Endocrinología y Metabolismo en Ginecología. Editorial Médica Panamericana. Buerios Aires. 1964.

3 LEON ISRAEL S.: Trastornos menstruales y Eesterilidad. Ed. Bernárdez S. A. Buenos Aires. 1969

4 MATEOS CANDANO $M$. et al.: Consideraciones sobre el manejo moderno del climaterio. Ginec. Obst. Mex. 25 : 433, 1969.

5 NOVAK SEEGAR: Tratado de Ginecología. 6a. Ed. Editorial Interamericana S. A. México, 1962 .

6 RILEY GARDNER M.: Endocrinología del climaterio. Clin. Obst. Ginec. 7: 432, 1964.

7 SAVILLE PAUL D.: Tratamiento de la osteoporosis postmenopáusica. Trat. Modernos. $3: 121,1968$.

8 KRETZSCHMAR W. A., STODDARD F.: Modificaciones fisiológicas del envejecimiento en la mujer. Clín. Obst. Ginec. 7: 451, 1964.

9 CASUCCIO C.: Concerning osteoporosis. J. Bone \& Joint. Surg. 448: 453, 1962. 
10 HARRISON M., FRASER R., MULLAN B. : Calcium metabolism in osteoporosis. Lancet $1: 1.015,1961$.

11 REIFENSTEIN E. C., ALBRIGHT F.: Metabolic effect of steroid hormones in osteoporosis. J. Clin. Invest. 26: 24, 1954.

12 SPRITZ N.: Aterosclerosis y Menopausia. Trat. modernos. 3: 114, 1968.

13 HERRICK J. B.: Clinical features of sudden obstruction of the coronary arteries. J.A.M. A. $59: 2.015,1912$.

14 REYNOLDS S. R.: Physiological bases of Ginecology and Obstetrics. Charles. C. Thomas, Springfield, Illinois, 1952.

15 PEARL M., et al.: Tratamiento de la paciente climatérica. Clin. Obst. Ginec. 7: 477, 1964.

16 ALBRIGHT F.: Estudies on Ovarian Dysfunction. Endocrinology. 20: 25, 1936.

17 FUGO N. W.: Diagnóstico y tratamiento de los trastornos menstruales. Clin. Med. Pág. 3,1961 .

18 DREYFUS G., et al.: Le traitement hormonal de la menopause. Sem. Therapeut. 2: 11, 1957.

19 MICHEL WOLFROMM H.: Ginecología Psicosomática. Toray Masson S. A. Barcelona, 1965.

20 KROGER W. S., FREED S. CH.: Ginecología Psicosomática. Salvat Ed. Barcelona, 1955.

21 McCANDLESS F. D.: Problemas emocionales ne el climaterio. Clín. Obst. Ginec. 7: 489, 1964.

22 DAVIS M. E.: Estrogenoterapia substitutiva a largo plazo después de la menopausia. Clin. Obst. Ginec. 7: 558, 1964.

23 GREENBLATT R. B.: Estrogen therapy for postmenopausal females. New England J. Med. 272: 305, 1965.

24 HAMBLEN E. C.: El climaterio, menopausia precoz, diagnóstico y tratamiento. Rev. Col. Obst. Ginec. 11: 603, 1960.

25 FUENZALIDA S., et al.: Estrogenoterapia en la postmenopausia. Rev. Col. Obst. Ginec. 18: 299,1967

26 GREENBLATT R. B.: Síndrome menopáusico. Trib. Méd. 2: 1, 1963.

27 CARDONA P. N., et al.: Valoración del FSH por la citología. Rev. Col. Obst. Ginec. 11: 401, 1960.
28 HAMBLEN E. C.: Terapia androgénica en la mujer. Rev. Col. Obst. Ginec. 11: 386, 1960.

29 CALDERON J. J., GARCIA G., MAQUEO M.: Tratamiento y evolución de la hiperplasia endometrial con progestágenos a dosis bajas. Ginec. Obst. Mex. 24: 311, 1969.

30 MORALES LEPE C., EQUILUZ LOPEZ B.: Tratamiento hormonal del síndrome climatérico. Reporte preliminar. Ginec. Obst. Mex. 22: 891, 1967.

31 PARSONS L., SOMMERS SH. C.: Gynecology. W. B. Saunders Company. Philadelphia. 1962.

32 RICAUD ROTHIOT L., WULFOVICH M., VALENZUELA S., CHANG D.: Sangrado Genital en la post-menopausia. Análisis de 88 casos. Ginec. Obst. Mex. 24: 235, 1968.

33 MEISELS A.: The menopause, cytohormonal study. Acta Cytol. 10: 49, 1966.

34 PLOTZ E. J.: New concepts in management of climateric and post-menopause. Chicago Med. 68: 957, 1965.

35 JAROLIN C., BERNARD L. I., STRAUS H. A. : Estrogenic substitution therapy with estradiol pellet implantation. Am. J. Obst. Gynec. 94: 170, 1966.

36 DAVIS M. E., STRANDFORD N. M., LANZ L. $\mathrm{H}$.: Estrogens and aging progress: detection, prevention and retardation of osteoporosis. J.A.M.A. 196: 219, 1966.

37 MEEMA H. E., BUNKER M. L., MEEMA S. : Loss of compact, bone due to menopause. Obst. \& Gynec. 26: 333, 1965.

38 INGULLA W.: Endocrine aspects of premenopausal metropathy. Gynec. Prat. 16: 127, 1965.

39 PAULSEN L.: Function of the postmenopausal ovary. Comparison of urynary estrogen and gonadotropin excretion and response to administration of F.S.H. in postmenopausal and ovariectomized women. Obst. \& Gynec. Survey 14: 215, 1959.

40 NOVAK E.: Hemorragia post-menopáusica. Clín. Obst. Gynec. 7: 489, 1964.

41 BARANKI T., JONES H.: Early premature menopause. A report of 6 cases with citogenetic findings. Am. J. Obst. Gynec. 96: $990,1966$.

42 HERSCHEL W. GORDON E.: The effect of digitalis therapy on the vaginal citology in 
post-menopausal females. Am. J. Obst. Gy nec. 94: 524, 1966.

43 TAYMOR L. M., RISCALLAH T. H. : Progestogen - estrogen. in the menopause. A dou ble blind study. Am. J. Obst. Gynec. 97: $460,1967$.

44 FURUHJELM MIRHAM: Urinary excretion of hormones during the climateric. Acta Obst. et Gynec. Scandinav. 45: 352, 1966.

45 MORALES GORDILLO I., PATIÑO BLANCO R.: Tratamiento del climaterio. Ginec. Obst. Mex. 143: 321, 1968.

46 FRAMPTON J.: Increased estrogen activity associated with post-menopausal bleeding. J Obst. Gynec. Brit. Cwlth 73: 137, 1966.

47 CACERES E., BARBOSA A.: Patología ovárica en pacientes mayores de 40 años. Rev. Col. Obst. Gynec. 19: 209, 1968.

48 GORDON D., PAULSEN C. A.: Premature menopause in $X O / X X / X X X / X X X X X$ mosaicism. Am. J. Obst. Gynec. 97: 85, 1967.
49 POLIAK A., JONES GEORGEANA, GOLDBERG B., SALOMON D., WOODRUFF J. D.: Effect of human chorionic gonadotropin on postmenopausal women. Am. J. Obst. Gynec. 101 : 731,1968

50 FERRAZINI F.: Gráficas promedio de la eliminación de los 17 cetosteroides totales en la orina de las 24 horas. Método de Drekter. Praxis 41: 964, 1952.

51 SAWARAGI I., WYNN R.: Ultrastructural localization of metabolic enzymes during the human endometrial cycle. Obst. \& Gynec. 34 : $50,1969$.

52 BOUT SELIS J., DENEEF J., ULLERY J., GEORGE O.: Histochemical and cytologic observations in the normal human endometrium. Obst. \& Gynec. 21: 423, 1963.

53 ATKINSON W., ENGLE E.: Studies on endometrial alkaline phosphatase during the human menstrual cycle and in the hormonetreated monkey. Endocrinology 40: 327 1947. 